\title{
FREQUENCY OF DIABETIC RETINOPATHY IN PATIENTS WITH TYPE-II DIABETES MELLITUS IN AN UPSCALE CLINIC IN KARACHI.
}

\footnotetext{
1. MBBS

House Officer

United Medical and Dental College Creek General Hospital Karachi.

2. FCPS, FRCS (Glasg)

Assistant Professor Ophthalmology United Medical and Dental College Creek General Hospital Karachi.

3. FRCOphth

Professor Ophthalmology

Dow University of Health Sciences Dr. Ruth K. M. Pfau Civil Hospital Karachi.
}

\section{Correspondence Address:}

Dr. Beenish Khan

Department of Ophthalmology

United Medical and Dental College

Creek General Hospital. Korangi,

Karachi.

beenish_aquarian@hotmail.com

Article received on:

13/03/2019

Accepted for publication:

$15 / 06 / 2019$

\section{Saad Nasir ${ }^{1}$, Beenish Khan², Muhammad Muneer Quraishy ${ }^{3}$}

ABSTRACT... Objectives: The objective of this study is to measure the current frequency of diabetic retinopathy in Karachi and the stage at which they present first to the outpatient department. Study Design: Cross sectional study. Setting: A private clinic setup in Karachi. Period: $1^{\text {st }}$ July 2015 to $30^{\text {th }}$ June 2016. Material \& Methods: In this study, 440 eyes of 220 diabetics were included and frequency of diabetic retinopathy was measured. Individuals ranging from $20-80$ years age were included. Ophthalmic plus systemic relevant history from every patient was taken in detail. Standard Snellen's chart was used to check the best corrected visual acuity (BCVA). Slit lamp examination was done along with fundoscopy with +90D and $+70 \mathrm{D}$ lens after dilatation with Tropicamide $1 \%$. All patients were examined for diabetic retinopathy. Along with it, stage of diabetic retinopathy, association of diabetic retinopathy with hypertension, age and duration of diabetes was also taken into consideration. Results: The frequency of diabetic retinopathy amongst 220 patients was found to be $15.9 \%$ while $6.6 \%$ of them were also having associated maculopathy. The stages of diabetic retinopathy were found to be $10.4 \%$ background diabetic retinopathy(BDR), $0.9 \%$ preproliferative diabetic retinopathy(PPDR), 3.4\% proliferative diabetic retinopathy(PDR) and $1.1 \%$ advance diabetic eye disease(ADED). Overall, $58.5 \%$ of the patients also had hypertension along with it. Conclusion: Nationwide studies are needed to be conducted to prevent this complication from progressing while the incidence of diabetic retinopathy is increasing very alarmingly among the society.

Key words: Diabetic Retinopathy, Frequency, Maculopathy, Pakistan, Karachi.

Article Citation: Nasir S, Khan B, Quraishy MM. Frequency of Diabetic Retinopathy in patients with Type-II diabetes mellitus in an upscale clinic in Karachi. Professional Med J 2020; 27(2):274-278. DOI: 10.29309/TPMJ/2020.27.2.3406

\section{INTRODUCTION}

Diabetes Mellitus is a non-transmissible metabolic syndrome, which is laddering up to be one of the leading cause of death worldwide. ${ }^{1}$ It is indicated by an increase in the blood glucose level due to a defect in insulin production. ${ }^{1}$ In a survey done by World Health Organization (WHO) in 2016, the occurrence of the disease was alarmingly increased to fourfold of that in 1980 , with $5.7 \%$ of the current world population suffering from the disease and is further expected to rise to $8.5 \%$ by $2040 .^{2}$ One year later to this, another survey stated the prevalence of global diabetes as $8.8 \%$ and is expected to rise to $9.9 \%$ by $2045 .{ }^{3}$ Whereas in accordance with the National Diabetes Survey, $19.4 \%$ of population of Pakistan is currently suffering from the disease. ${ }^{4}$

Diabetic retinopathy is the most frequent eye disease associated with diabetes, which goes undetected in its earlier phase, since visual deterioration occurs gradually. According to the World Health Organization (WHO), diabetic retinopathy is the fifth leading cause of preventable blindness worldwide. ${ }^{5}$

The prevalence of diabeticretinopathyis increasing alarmingly worldwide. In 2012, the estimated population globally affected by the disease was reported to be approximately 93 million with, $18 \%$ having proliferative diabetic retinopathy (PDR) , $22.5 \%$ with macular edema and $30 \%$ with visionthreatening diabetic retinopathy (VTDR). ${ }^{6,7}$ The population of Pakistan currently stands at around 205 million. $^{8}$ In 2006, the frequency of diabetic retinopathy in a community based study in Karachi was estimated to be $15.7 \% .{ }^{9}$ In Pakistan the current data suggests the prevalence of the 
disease varies due to inadequate data and the fact that most of the cases are underdiagnosed. ${ }^{10}$

Diabetes Mellitus is associated with many micro and macro vascular pathologies with its advancement. People who suffer from diabetes for longer durations tend to have prolonged high blood glucose levels, causing smaller retinal vessels to leak their content and ultimately irreversible deterioration of the vision occurs. ${ }^{11}$ This gradual decline of the vision if detected and treated in earlier stages can decrease the likelihood of developing blindness in $90 \%$ of the cases. ${ }^{12}$ Hypoxia induced neovascularization by the vascular endothelial growth factor alpha (VEGF) has been known to be one crucial factor in the progression of the disease. ${ }^{11}$ Recent studies have shown that using Anti-VEGF monoclonal antibodies have benefited the patients by slowing down the progression of the disease and are now being considered line of defense. ${ }^{11}$ The prime risk factors which can lead to diabetic retinopathy include hyperglycemia, hypertension and dyslipidemia and are relatively modifiable. ${ }^{13}$ Many aspects of the disease are yet to be made understood. There is a lack of adequate screening methods and association of risk factors in mass population which makes it one of the uprising cause of preventable blindness.

Apart from lots of studies regarding the risk factors of diabetic retinopathy, population based data about frequency of diabetic retinopathy is relatively scarce. The Rationale of this study is to provide the current population based data regarding frequency of diabetic retinopathy in Karachi.

\section{Operational Definitions}

\section{Diabetic}

All the diagnosed patients of diabetes (insulin or non insulin dependent) whether with good glycaemic control or uncontrolled as confirmed by $\mathrm{HbA} 1 \mathrm{C}$.

Duration of diabetes ranging from one month to more than $30 \mathrm{yrs}$.

\section{No Diabetic Retinopathy}

No signs of diabetic retinopathy

\section{Background Diabetic Retinopathy}

Characterized by micro aneurysms, dot and blot hemorrhages and hard exudates.

\section{Pre-proliferative Diabetic Retinopathy}

Characterized by cotton wool spots, venous changes, intraregional micro vascular anomalies (IRMA) and deep retinal hemorrhages

\section{Proliferative Diabetic Retinopathy}

Characterized by neovascularization on or within one disc diameter of the disc (NVD) and/or new vessels elsewhere (NVE) in the fundus.

\section{No Maculopathy}

No signs of focal or diffuse macular edema and no sign of ischemia

\section{Focal Macular Edema}

Well-circumscribed retinal thickening associated with complete or incomplete rings of exudates

\section{Clinically Significant Macular Edema}

As defined by Early Treatment Diabetic Retinopathy Study (ETDRS).

- Retinal thickening within $500 \mu \mathrm{m}$ of the center of the macula.

- Exudates within $500 \mu \mathrm{m}$ of the center of the macula, if associated with retinal thickening (which may be outside the $500 \mu \mathrm{m}$ ).

- Retinal thickening one disc area $(1500 \mu \mathrm{m})$ or larger, any part of which is within one disc diameter of the center of the macula.

\section{Advanced Diabetic Eye Disease}

Characterized by tractional retinal detachment (TRD), significant persistent vitreous hemorrhage and neovascular glaucoma (NVG).

\section{METHODOLOGY}

\section{Study Design}

Cross sectional study at a private clinic setup at Karachi. It was conducted over one year starting from 1st July 2015 to 30th June 2016.

\section{Sample Size}

440 eyes of 220 patients were included under the study by non probability purposive sampling. 


\section{Inclusion Criteria}

1. All patients who fulfilled the criteria of Diabetics.

2. Subjects of any gender male or female.

3. Subjects age from 20-80 years.

4. Subjects of any duration of diabetes including newly diagnosed diabetics.

\section{Exclusion Criteria}

1. Patients with ocular diseases other than diabetic retinopathy especially posterior segment diseases.

2. Any history of retinal laser therapy or other ocular surgeries

3. All the patients with media opacities that hinder fundus visualization.

\section{Data Collection}

Selected subjects from the out patient department of a private setup at Taj Medical Complex Karachi underwent ophthalmic examination including slit lamp examination along with $+90 \mathrm{D}$ and $+78 \mathrm{D}$ lens examination after pupillary dilatation with $1 \%$ of Tropicamide. 440 diabetic eyes were selected. Whole procedure was explained and informed consent was taken. Refraction and Fundus fluorescein angiography of all subjects was done to control confounders. Stage of diabetic retinpoathy was labeled according to the clinical findings and fundus fluorescein angiography. Follow up of the patient was advised according to the severity of diabetic retinopathy to see the progression.

\section{Data Analysis}

Statistical Packages for Social Science (SPSS-
22) was used to analyze data. Mean was used for quantitative variables (age). Frequency and percentage was calculated for qualitative variables like gender, type of diabetes, stage of diabetic retinopathy and maculopathy and management.

Data was stratified in multiple groups according to gender, duration of diabetes and diabetic retinopathy status. Than the calculations through chi square were taken for both groups to see the effect of each variable accordingly.

\section{RESULTS}

A total of 440 eyes of 220 diabetic patients were included in the study. Overall, 109 (49.5\%) were male participants, while 111 (50.5\%) were female in the studied population. The participants were divided in two groups on the basis of duration of diabetes, out of which 153 (69.5\%) of the individuals were having diabetes since less than 10 years while 67 (30.5\%) were having diabetes for more than 10 years. The frequency of diabetic retinopathy was $15.9 \%$ out of which $6.6 \%$ of the individuals had associated maculopathy. There was no statistically significant relation between the gender and duration of the diabetes with the occurrence of disease $(p>0.05)$. Independent $T$ test was applied to the age and the occurrence of diabetic retinopathy and no statistical significance was determined $(p>0.05)$. The data suggest that 129 (58.6\%) individuals had associated hypertension although there was no statistically significant relation with diabetic retinopathy $(p>0.05)$.

\begin{tabular}{|c|l|c|c|c|c|}
\hline \multicolumn{2}{|c|}{ Gender } & Frequency & Percent & Valid Percent & Cumulative Percent \\
\hline \multirow{3}{*}{ Valid } & Male & 109 & 49.5 & 49.5 & 49.5 \\
\cline { 2 - 6 } & Female & 111 & 50.5 & 50.5 & 100.0 \\
\cline { 2 - 6 } & Total & 220 & 100.0 & 100.0 & \\
& \multicolumn{4}{r}{ Table-I } \\
\end{tabular}

\begin{tabular}{|c|c|c|c|c|c|}
\hline \multicolumn{2}{|c|}{ Duration of Diabetes } & \multirow{2}{*}{$\begin{array}{c}\text { Frequency } \\
153\end{array}$} & \multirow{2}{*}{$\begin{array}{c}\text { Percent } \\
69.5\end{array}$} & \multirow{2}{*}{$\begin{array}{c}\text { Valid Percent } \\
69.5\end{array}$} & \multirow{2}{*}{$\begin{array}{c}\text { Cumulative Percent } \\
69.5\end{array}$} \\
\hline & $0-10$ years & & & & \\
\hline Valid & $>10$ years & 67 & 30.5 & 30.5 & 100.0 \\
\hline
\end{tabular}




\begin{tabular}{|l|l|c|c|c|c|}
\hline \multicolumn{2}{|c|}{ Associated Hypertension } & Frequency & Percent & Valid Percent & Cumulative Percent \\
\hline \multirow{3}{*}{ Valid } & Yes & 129 & 58.6 & 58.6 & 58.6 \\
\cline { 2 - 6 } & No & 91 & 41.4 & 41.4 & 100.0 \\
\cline { 2 - 6 } & Total & 220 & 100.0 & 100.0 & \\
& & & Table-III &
\end{tabular}

\section{DISCUSSION}

In our study, there were 440 eyes of 220 patients included and frequency was measured which turned out to be $15.9 \%$, which was very close to one study done in $2006 .{ }^{9}$ In that study the frequency of diabetic retinopathy was measured to be $15.7 \% .{ }^{9}$ In a hospital based study conducted in Karachi, the frequency of diabetic retinopathy measures to as high as 55.3\%. ${ }^{14}$ The reason for this extreme variation in the frequency is due to fact that many cases remain underdiagnosed. In a similar study conducted in China, the frequency of diabetic retinopathy was found to be $6.5 \%$ of the studied population ${ }^{15}$ whereas higher frequency $(32 \%)$ was seen in patients of India. ${ }^{16}$

Regarding the prevalence in western countries, US population showed $28.5 \%$ patients positive for diabetic retinopathy with $4.4 \%$ of visual threatening disease. ${ }^{17}$ Markedly different results were shown in a similar study that was conducted in Spain, that showed the prevalence of $12.3 \%$. These results are near to our study. ${ }^{18}$

In our study, the $15.9 \%$ of the patients with diabetic retinopathy were grouped according to stages. The frequency of background diabetic retinopathy (BDR) was measured to be $10.4 \%$ while, the frequency of preproliferative stage was found to be $0.9 \%$ (PPDR), proliferative stage was visualized in $3.4 \%$ (PDR) and advance diabetic eye disease (ADED) was found to be seen in $1.1 \%$ of the patients. Other minor findings include, maculopathy in $6.6 \%$, associated hypertension in $58.6 \%$.

In future, broader spectrum researches are needed to be done to assess the frequency of this catastrophic vision threatening diseases and this has to be done nationwide. There is an immaculate need for taking extreme measures to spread awareness to the patients suffering from diabetes about this complication on larger scales, so that more people can be diagnosed earlier and can be monitored throughout the course of the disease.

There are a number of limitations to our study. The data collected in our study was from only one private clinic which leads to sampling bias, as our study does not target all the individuals in a society. In our study there was no evidential proof for a patient to be considered a diabetic. In our study, the nature of employment or educational status was not considered to be primordial basis of the early or late progression of the disease.

\section{CONCLUSION}

To summarize, this study provides the current frequency of diabetic retinopathy, a serious progressivevision threatening condition. However, this complication of diabetes can be avoided by early detection and prompt management.

\section{Conflicts of Interest}

Authors do not have financial interest.

Copyright $\odot 15$ June, 2019.

\section{REFERENCES}

1. Sohail M. Prevalence of diabetic retinopathy among type 2 diabetes patients in Pakistan - vision registry. Pak J Ophthalmol. 2014; 30(4):204-12.

2. Global report on diabetes. France: The World Health Organization; 2016:88 p.

3. IDF Diabetes Atlas. Eighth edition; 2017.

4. Jawa A, Assir MZK, Riaz SH, Chaudhary R, Awan F, Akram J. A simple integrated primary health care based model for detection of diabetic retinopathy in resource-limited settings in Pakistani population. Pak J Med Sci. 2016; 32(5):1102-06. doi:10.12669/ pjms.325.10955.

5. Prevention of blindness and visual impairment. World Health Organization. Available from: http://www.who.int/ blindness/causes/en/. 
6. Yau JWY, Rogers SL, Kawasaki $R$ et al. Global prevalence and major risk factors of diabetic retinopathy. Diabetes Care. 2012; 35(3):556-64. doi:10.2337/dc11-1909.

7. Diabetic Retinopathy - Asia Pacific Nov 2013. Available from: https://www.aao.org/topic-detail/diabeticretinopathy-asia-pacific

8. Pakistan Demographics Profile 2018. Available from: https://www.indexmundi.com/pakistan/ demographics_profile.html.

9. Qureshi MBJ, Khan AJ, Khan MD, Khan K. Prevalence of diabetic retinopathy among individuals screened positive for diabetes in five community-based eye camps in northern Karachi, Pakistan. J Ayub Med Coll Abbottabad. 2006; 18(3):40-3.

10. Kovarik JJ, Eller AW, Willard LA, Ding J, Johnston JM, Waxman EL. Prevalence of undiagnosed diabetic retinopathy among inpatients with diabetes: The diabetic retinopathy inpatient study (DRIPS). BMJ Open Diabetes Research \& Care. 2016; 4(1):e000164. doi:10.1136/bmjdrc-2015-000164.

11. Crawford TN, Alfaro DV, Kerrison JB \& Jablon EP. Diabetic retinopathy and angiogenesis. Curr Diabetes Rev. 2009; 5:8-13.

12. Early treatment diabetic retinopathy study research group. Early photocoagulation for diabetic retinopathy. ETDRS report number 9. Ophthalmol. 1991 May; 98:766-85.
13. Esteves J, Laranjeira AF, Roggia MF, Dalpizol M, Scocco C, Kramer CK, et al. Diabetic retinopathy risk factors. Arq Bras Endocrinol Metabol. 2008; 52:431-41.

14. Alkhairy S, Rasheed A, Aziz F, Nawaz S. Frequency of diabetic retinopathy in Karachi, Pakistan: A hospital based study. Journal of Dow Uni Health Sci. 2015 Sep $1 ; 9(2)$.

15. Xie $\mathrm{X}, \mathrm{Xu} \mathrm{L}$, Yang $\mathrm{H}$ et al. Frequency of diabetic retinopathy in the adult population in China: The Beijing Eye Study 2001. Int Ophthalmol. 2009; 29:48593.

16. Bansal P, Gupta RP, Kotecha M. Frequency of diabetic retinopathy in patients with diabetes mellitus and its correlation with duration of diabetes mellitus. Med $\mathrm{J}$ Dr D.Y. Patil Vidyapeeth. 2013; 6(4):366-9.

17. Zhang X, Saaddine JB, Chiu CF, Cotch MF, Cheng YJ, Geiss LS, et al. Prevalence of diabetic retinopathy in the United States, 2005-2008. JAMA (Reprinted). 2010; 304(6):649-56.

18. Poncelas AR, Jimenez SM, Casellas A, La Puente JFB, Nadal JF, Simarro FL, et al. Prevalence of diabetic retinopathy in individuals with type 2 diabetes who had recorded diabetic retinopathy from retinal photographs in Catalonia (Spain). $\mathrm{Br} \mathrm{J}$ Ophthalmol. 2015; 99(12):1628-33.

\begin{tabular}{|c|l|l|l|}
\hline \multicolumn{3}{|c|}{ AUTHORSHIP AND CONTRIBUTION DECLARATION } \\
\hline Sr. \# & \multicolumn{1}{|c|}{ Author(s) Full Name } & \multicolumn{1}{|c|}{ Contribution to the paper } & Author(s) Signature \\
\hline 1 & Saad Nasir & $\begin{array}{l}\text { Data collection, analysis } \\
\text { and interpretation and } \\
\text { manuscript writing. } \\
\text { Study concept and design } \\
\text { and manuscript writing. } \\
\text { Manuscript review. }\end{array}$ \\
\hline 3 & Beenish Khan & M. Muneer Quraishy & \\
\hline
\end{tabular}

